\title{
Exploring property value effects of ferry terminals: Evidence from Brisbane, Australia
}

\author{
Chi-Hong (Patrick) Tsai \\ University of Sydney, Australia \\ chi-hong.tsai@sydney.edu.au
}

\author{
Matthew Burke \\ Griffith University, Australia \\ m.burke@griffith.edu.au
}

\author{
Corinne Mulley \\ University of Sydney, Australia \\ corinne.mulley@sydney.edu.au
}

\begin{abstract}
Property value effects of linear river ferries that service multiple stops in cities are under-explored. The Brisbane CityCat, CityHopper, and CityFerries combine to form a ferry system with 24 terminals. A geographically weighted regression (GWR) approach is used to determine property value effects of the system. Cross-sectional property data is used in combination with a set of neighborhood variables derived from 2011 census data, spatial feature location, and transport datasets (roads, busway and train station locations) for the city. The preferred global model had a good fit and showed expected signs for all parameters, showing that property prices tended to decline with distance from ferry terminals, when controlling for other variables. For every kilometer close a location is to a ferry terminal, there is an expected price increase of 4 percent on average, across the study area. The GWR local model also had good fit and suggested property value gains around specific terminals. Visual inspection suggests that locations where more ferry-oriented development opportunities have been taken in recent decades are the sites with the greatest positive property value effects. The implications are that land developers are justified in seeking ferry terminals to service their developments.
\end{abstract}

Keywords: land value uplift, ferry, geographically weighted regression, accessibility of public transport

\section{Article history:}

Received: September 15, 2014

Accepted: April 25, 2014

Available online: July 2, 2015

\section{Introduction}

Cities in both the developed and developing worlds have recently introduced linear passenger ferry systems that provide relatively frequent services along rivers or parallel to shorelines, servicing multiple stops (Thompson, Burroughs, and Smythe 2006). Examples include the East River Ferry in New York, the Chao Praya Express in Bangkok, the Thames Clippers river bus in London, UK, and the CityCat ferry in Brisbane, Australia. All provide more than simple cross-river services. They feature multiple

Copyright 2015 Chi-Hong (Patrick) Tsai, Corinne Mulley, Matthew Burke \& Barbara Yen http://dx.doi.org/10.5198/jtlu.2015.562

ISSN: 1938-7849 | Licensed under the Creative Commons Attribution - Noncommercial License 3.0

The Journal of Transport and Land Use is the official journal of the World Society for Transport and Land Use (WSTLUR) and is published and sponsored by the University of Minnesota Center for Transportation Studies. This paper is also published with sponsorship from WSTLUR and the Institutes of Transportation Studies at the University of California, Davis, and the University of California, Berkeley. 
stops, relatively short headways, and operate from morning until night, across weekdays and weekends. These river ferries are perceived as offering high-quality transit service for commuters, students, shoppers, tourists, and a range of other travelers. The introduction of sleek, fast ferries capable of operating at or above 25 knots and with reliability due to a lack of congestion or crashes help explain why ferry systems are being introduced to offer quality public transport and help revitalize cities (Weisbrod and Lawson 2003). In both Brisbane and New York, private land developers have contributed funds toward ferry terminals based on the assumption that the presence of these services will raise land values/rents for their developments (Burke and Sipe in press). Developers and governments alike are using linear ferry systems to produce ferry-oriented development, with ferry investments seen as helping revitalize neighborhoods in places such as New Jersey (Cervero et al. 2004 p.220). The question addressed by this paper is whether there are real estate or property gains that result from increased residential accessibility to linear urban ferry systems.

This paper explores the relationships between property value and ferry public transport-specifically, ferry services designed for use by commuters - using the Brisbane ferry system as a case study. Use is made of cross-sectional property sales data for the city, along with a range of property-specific variables and other socio-economic and spatial parameters to control for the internal characteristics of the property and neighborhood effects.

The paper is structured as follows: the next section provides a discussion of previous research on linear ferries and on property value effects of public transport services. This highlights issues that should be considered when exploring the effects of ferry systems. The Brisbane ferry system is summarized next, before addressing the methodology adopted and the data used in this analysis. The results are then provided and interpreted, showing results both in line and at odds with expectations. The paper concludes with a discussion of what the results may mean for broader transport and land-use policy and practice and avenues for further research.

\section{$2 \quad$ Impacts of public transport systems on land values}

A number of studies have explored ferries as a mode choice (Outwater et al. 2003; Schwanen and Mokhtarian 2005). However, there has as yet been no attempt to identify the impact of property values from urban "parallel" or linear ferry systems that have been emerging in recent times in various cities. There has, however, been significant work exploring the impacts of other types of public transport investment. Most of the modes have been covered in this exploration-light rail, metro, heavy rail, and bus rapid transit (BRT).

The motivation for investigating value uplift created by transport infrastructure has been partly driven by government interest in capturing value uplift to help pay for improved transport infrastructure and services. Most of the research in this area follows the theories advocated initially by von Thunen (1826) in the early nineteenth century in which a simplified model of a flat featureless plain with constant population density led to the conclusion that market size is determined by transport cost. Coupled with work by Alonso (1964) and Muth (1969), the theoretical framework for the relationship between accessibility and land values has been developed so as to identify how accessibility to a feature explains value differences for properties in the surrounding area. Rents tend to fall as distances increase from features that offer accessibility benefits to landholders. In the public transport context, features such as train stations offer accessibility to central business districts and their many opportunities for work, retail, and leisure. Those who live within close proximity of stations benefit from reduced time and costs to access these opportunities. These lower generalized costs tend to drive rents higher close to stations, and rents typically fall as distance from the station increases. 
Empirical studies to quantify land value uplift as a result of new or improved transport infrastructure have had mixed results. RICS $(2002)$ and Smith and Gihring $(2006,2009)$ together provided major reviews of more than 100 international studies on the impact of public transport on property values, focused almost exclusively on the impact of rail projects (heavy rail, metro, and light rail). These show considerable variation in uplift through ranges of negative, negligibly positive, and up to 25 percent positive impacts for residential properties. Studies on the value uplift produced by bus-based infrastructure are less evident in the literature, although again, there are very varied results ranging from around $+2 \%$ in Beijing, China (Cervero and Kang 2011), to $+16 \%$ in Pittsburg (Perk and Catala 2009). There is an absence of studies looking at the value uplift created by new or improved ferry services.

Debrezion et al. (2007) suggest three key issues to consider for studies of public transport, accessibility, and property values. Firstly, public transport stops differ from one another in the types of services they offer. Frequencies, service coverage, stopping patterns, and connections may all vary. This creates differences in the impacts particular stops have on surrounding property values. One would expect the ferry terminals in a system with the greatest frequencies, cheapest services, highest quality facilities, and best connections to bus networks would have higher land value premiums due to accessibility around them. Property (re-)development opportunities may be also be greater around some ferry terminals than others, further increasing the potential for value uplift in some locations and stymying it in others.

Second, property value effects may substantially differ by land-use type. Residential properties may be very differently affected than industrial or commercial properties, with owners of the latter being more likely to internalize potential land value uplift from the announcement of transport improvements. Medium- and high-density residential properties may be differently affected than low-density properties. As noted by Debrezion et al (2007 p.165), rail stations tend to have strong local impacts on commercial properties, being a focal node and gathering point in a neighborhood, but they have a wider impact on residential properties. It is not known if river ferry terminals produce similar effects.

Third, socio-economic and demographic variables play a significant role in influencing the impacts of transit stops on property values. Disparities in socio-economic status and ethnicity produce higher ridership on public transport in some neighborhoods than others. In many cities, low-income households are particularly attracted to locations serviced by public transport, where residents become captive riders, particularly where they have no private motor vehicle alternatives (Nelson 1992). By contrast, river ferry services are often seen as premium public transport services, offering uncongested, scenic, high-amenity travel with few stops, linking suburban areas with destinations such as central business districts and universities for commuting purposes. These ferries may actually appeal to higher socioeconomic status (SES) households or at least to a broader range of social groups. But this uncertainty as to the impact of socio-demographic variables points to the importance of including such variables in the analysis to control for the neighborhood location of the properties under consideration.

Most previous studies report highly variable average levels of value uplift for residential properties around new or improved public transport infrastructure. In part this is due to the different locations of studies, where diverse responses to accessibility might be anticipated. However, some of the differences must also be due to methodological variation across studies. Early research used a quasi-experimental approach with before and after studies for a "treatment" area and a "control" area. However, this approach failed to successfully isolate the impact due to public transport improvement from other impacts in what is a complex market. More sophisticated modeling has concentrated on using hedonic models. Most recently, with developments in econometric modeling, hedonic models have developed from using an OLS methodology to one that takes account of potential spatial variation and spatial correlation that is common when using geographical data, where variation arises particularly from household preferences. Spatial lag, spatial error, and multi-level methodologies have been developed to compensate for the way 
in which spatial dependency breaks the "well-behaved" assumptions of the error terms in OLS. However, these methodologies allow the estimation of a single equation model that may not suffer from the impact of spatial dependency but cannot be used to reveal where spatial variability exists.

Geographically weighted regression (GWR), developed by Fotheringham et al. (2002), takes account of spatial dependency in the estimation process, with spatial variation shown as mapped output. GWR provides a number of advantages, including the resolution of spatial non-stationarity, by taking account of the XY coordinates in estimating parameter values and geographical location in the intercepts, respectively. For public transport infrastructure, the first application of GWR was to look at value uplift in the northeast of England for light rail (Du and Mulley 2006; 2007), although it has since been used in other transport contexts, such as rail demand forecasting (Blainey 2010) or residential rents (Lochi and Axhausen 2010).

A literature gap therefore exists on the impact of linear ferry development as a mode of public transport, particularly for commuting. The paper addresses this gap. The next section outlines the characteristics of the case study area in Brisbane, Australia, before turning to the methodology, analysis, and results.

\section{The Brisbane ferry system}

Brisbane is a city of more than two million residents located on the east coast of Australia. Brisbane Transport (a division of the Brisbane City Council) provides three types of passenger ferry on the Brisbane River. Operated under contract by Transdev, a private operator, these are the CityCat, CityHopper, and CityFerry services. The CityCat system was recently described by Sipe and Burke (2011). The CityCat route runs from the University of Queensland downstream through the central business district (CBD) and eventually to North Shore Hamilton, servicing 16 terminals. The CityCat ferries themselves are either 149 or 162 passenger catamarans that operate at a maximum cruising speed of 25 knots. The CityHopper is a free frequent service operating in the inner city only from North Quay in the CBD to Sydney Street, servicing eight terminals, at maximum speeds of around 15 knots. Both these routes are supplemented by cross-river CityFerry services that supplement key cross-river services already provided by CityCat or CityHopper routes (Teneriffe-Bulimba; Thornton Street-Eagle St Pier) or link a cross-river terminal to select CityCat services (Norman Park-New Farm Park). In total, there are 24 ferry terminals in the Brisbane system. Each terminal uses so-called 'spud barges'-rectangular floating pontoons connected to four tall posts on each corner that float up and down with tides and waves but do not move horizontally-connected by ramps to the shoreline. Services at most terminals include seating, information, and shelter, with some terminals also featuring ticketing machines, toilets, and/or connections to Brisbane city bus services. CityCat vessels, routes, and terminal locations for all Brisbane's ferries are provided in Figure 1.

Land developers have paid for part or all of the construction costs for the Regatta, Hamilton North Shore, and Tenerife terminals on the Brisbane River, to ensure ferries service their developments. The last two terminals opened in 2012 and 2013, respectively.

Apart from ferries, opportunities for crossing the river in Brisbane for access to different activities are limited by the existence of 12 bridges and tunnels in the corridor that the ferry system services, including bridges immediately upriver and downriver of the end terminals. Of these bridges and tunnels, nine are located in the $\mathrm{CBD}$, one is for rail only, two have busway crossings, two are restricted to motor vehicles only, and two are pedestrian and bicycle bridges. 

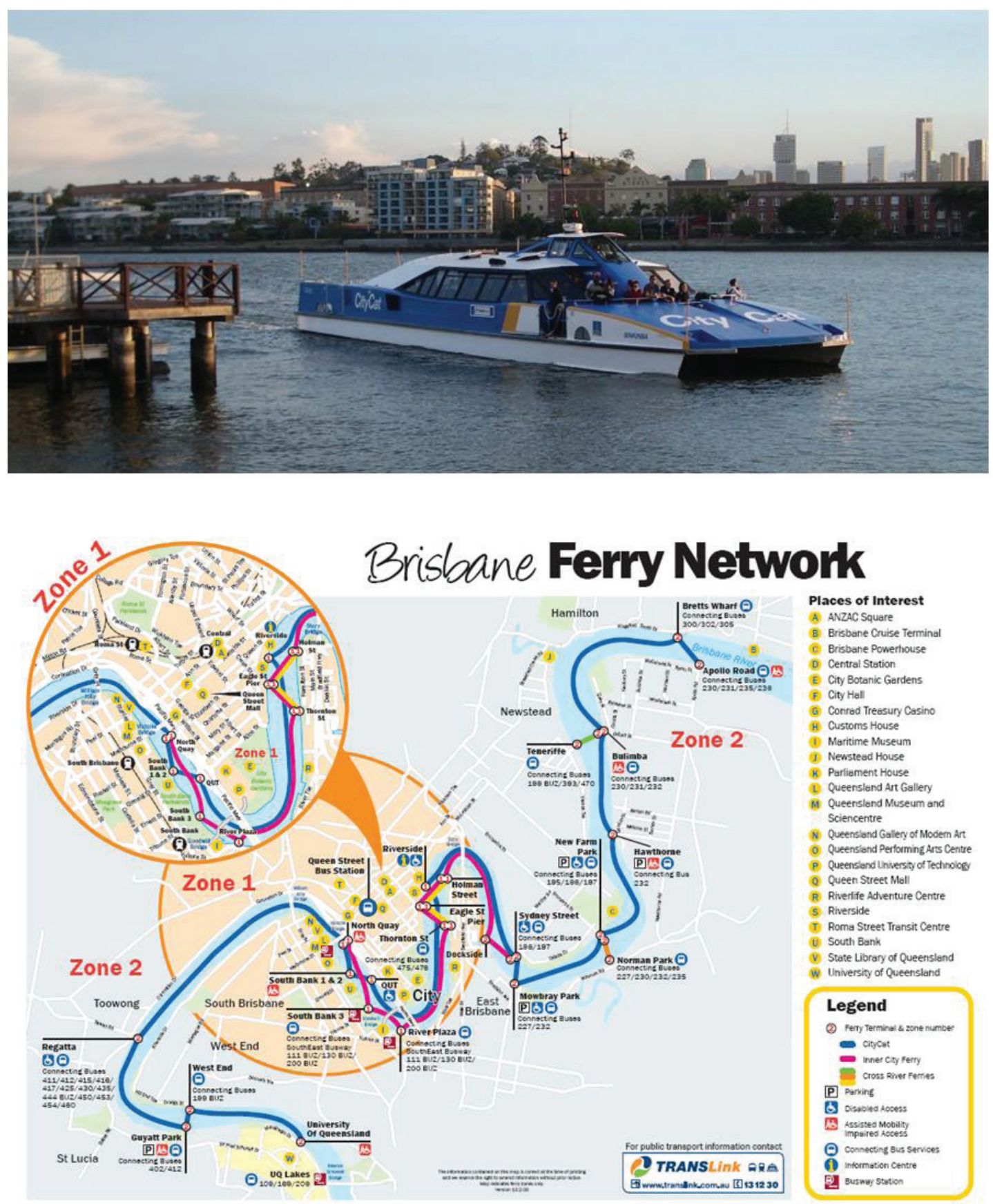

Figure 1: CityCat vessel (top, source: M. Burke); route and terminal locations for the Brisbane CityCat system, 2013 (bottom, source: TransDev)

In addition to ferries, Brisbane has a large commuter rail network of just over 200 kilometers that connects to the nearby cities of the Sunshine Coast and Gold Coast. Operated by a division of the Queensland Government, the CityRail network has relatively low ridership on a world scale. Service frequencies are 30 minutes off-peak in the outer suburbs and only recently improved to 15 minutes (or better) in the inner suburbs. The Brisbane City Council runs extensive bus services for the more than 
one million residents in its very large municipal area, in addition to contracting out the ferry operations. Many of the bus services run on dedicated busways that Hoffman (2008) described as "Quick-ways," since they are fully segregated from other traffic, with average stop spacings of more than one kilometer. In Greater Brisbane, and outside Brisbane City's jurisdiction, a range of private bus companies are contracted to supply operations targeted at commuter and local demands. Translink, a division of the Queensland Department of Transport \& Main Roads, oversees the entire public transport system, providing integrated fares and managing contracts and subsidies. Despite extensive infrastructure, services are not fully integrated. Most travel in the city is made by private motor vehicle. South East Queensland Travel Survey data for 2009 (Transport of Main Roads 2012) revealed that the mode share for public transport is only around 8 percent of all trips. Of the more than 80 million public transport trips made annually, just fewer than six million are made by ferry, giving ferries a 7.5 percent share of the public transportation trips.

\section{$4 \quad$ Methods}

GWR is most conveniently explained by reference to a traditional cross-sectional regression model, as described by Fotheringham et al. (2002), with this model written as:

$$
Y_{i}=\beta_{0}+\sum_{k} \beta_{k} x_{k i}+\varepsilon_{i}
$$

where $Y_{i}, x_{k i}$ and $\varepsilon_{i}$ are dependent variables, $k^{\text {th }}$ is an independent variable, and the Gaussian error respectively at location $i$.

The GWR methodology expands this model to a form that allows for local variations in the parameter values, which take account of the coordinates of individual regression points. If the dependent variable has the coordinates $\left(\mathrm{u}_{\mathrm{i}}, \mathrm{v}_{\mathrm{i}}\right)$, the model expressed in (1) above can be rewritten as the following GWR local model:

$$
Y_{i}\left(u_{i}, v_{i}\right)=\beta_{0}\left(u_{i}, v_{i}\right)+\sum_{k} \beta_{k}\left(u_{i}, v_{i}\right) x_{k i}+\varepsilon_{i}
$$

where $\left(u_{i}, v_{i}\right)$ is the $x-y$ coordinate of the ith location.

The parameters are estimated at the location $\left(\mathrm{u}_{\mathrm{i}}, \mathrm{v}_{\mathrm{i}}\right)$ using a weighted least squares method and a predicted value of $y$ effectively giving a regression at each point of the dataset. Estimation is a trade-off between efficiency and bias in the estimators with a weighting process using spatial kernels that capture the data points to be regressed by moving the regression point across the region. The results are sensitive to the choice of weights and spatial kernel.

This paper uses the newly released GWR4 software (version 4.0.72) developed in partnership between the National Centre for Geocomputation (NUIM), Ireland, and Ritsumeikan University, Japan. This version provides some important improvements over earlier releases of the software; particularly relevant is that it now allows the flexibility to use a semi-parametric (partial linear) GWR model form, incorporating both fixed and geographically varying explanatory variables. A golden searching routine and a differences test identifying variables that vary over the whole of the study area uses AIC goodness of fit measure as the basis for choosing an optimal model. The advantage of using a semi-parametric approach is that including explanatory variables as fixed when they do not vary significantly over space can both improve the overall model fit and provide a model that is more conceptually satisfactory. It should be noted that even when a variable is statistically significantly varying over geographical space, this does not mean that every data point is statistically significantly different from zero. For interpretation, it is particularly important to consider the combination of parameter estimates against their associated tvalues so as not to identify significant geographical variation to locations where it does not exist. 


\subsection{Modeling approach and data acquisition}

House prices are determined by the internal characteristics of the property, the neighborhood in which it is located, and the accessibility of the house location. The interest of this paper is in the underlying land value and its relationship with different accessibility measures, and thus the modeling approach must control for the internal characteristics of the property and its neighborhood. The house price is the dependent variable, which is related to the explanatory variables as shown in Equation 3, where C, $\mathrm{N}$, and $\mathrm{T}$ are respectively vectors of the internal property characteristics, neighborhood features, and transport accessibility measures.

$$
P_{i}=f(C, N, T)
$$

The study area was defined by a $2 \mathrm{~km}$ buffer either side of the centerline of the river. This was chosen to ensure that all properties that could be affected by accessibility to terminals were captured, given the 85 th percentile access to Brisbane ferry terminals was known to be $1.54 \mathrm{~km}$ from a previous analysis of South East Queensland household travel surveys (Burke and Brown 2007). The dependent variable $P_{i}$ is 2011 transaction price data from RPdata, a commercial firm which combines data from different sources to provide details of the transaction price, property type (house or unit), area size, number of bedrooms and bathrooms and the number of parking places. The study area included 2832 observations on house prices for analysis.

The internal characteristics of the property are captured by the number of bedrooms, the number of bathrooms, the number of parking places, and whether the property is a house or unit. Unfortunately, the area size of the property, which has been shown to be significant in many studies in the literature, could not be used in this analysis because the area size for units is total land area of all units within a development. Table 1 shows the descriptive statistics for the data, including minimum, maximum, mean, and standard deviation values.

The neighborhood features were controlled by a number of variables, collected at the SA1 level (the smallest geography available) from the 2011 Census, as shown in Table 1. The SA1 geography is population-based, with each SA1 aiming to contain 400 persons (with a minimum of 200 and a maximum of 800). Each property price observation was linked to the associated SA1 demographic variables so that all properties lying in the same SA1 area would be associated with the same census values. The percent unemployment and the percent migration ${ }^{1}$ are expected to be negatively associated and income positively associated with house prices, respectively. No prior expectations are made concerning the age variable, but the nature of a suburb may well be affected by the age structure of its residents. This has been found to be important in other studies.

Accessibility variables were calculated using GIS and are the network distances for each variable. A variety of accessibility variables were calculated: to the nearest primary school, to the nearest BRT stop, to the $\mathrm{CBD}$, to the nearest ferry wharf, and to the nearest station. The distance to the nearest BRT stop was removed from the analysis since this is highly correlated with distance to the CBD ( $r=0.901$, significant at the 1 percent level). In interpreting the variable of distance to the CBD, it should be remembered that this also captures the impact of distance to nearest BRT stop. In general, it would be expected that there is a negative relationship between these accessibility variables and house prices, reflecting that a longer distance of access would serve to decrease house prices, everything else being equal.

\footnotetext{
${ }^{1}$ Migration percentage here means net overseas migration (NOM) and is the percentage of net gain or loss of population through immigration to Australia and emigration from Australia. Data provided by the Department of Immigration and Border Protection is used by the Australian Bureau of Statistics to calculate the official NOM estimates each quarter.
} 
Table 1: Descriptive statistics of variables in the model

\begin{tabular}{|l|c|c|c|c|c|c|}
\hline & $\begin{array}{c}\text { Unit of } \\
\text { measurement }\end{array}$ & $\mathrm{N}$ & Minimum & Maximum & Mean & Std. Deviation \\
\hline Price & $\$$ & 2832 & $96,500.00$ & $4,800,000.00$ & $645,582.79$ & $413,621.38$ \\
\hline Bedrooms & number & 2832 & 0.00 & 9.00 & 2.65 & 1.09 \\
\hline Baths & number & 2832 & 1.00 & 7.00 & 1.72 & 0.72 \\
\hline Parking & number & 2832 & 0.00 & 11.00 & 1.44 & 0.80 \\
\hline Type & House/Unit & 2832 & 0.00 & 1.00 & 0.48 & 0.50 \\
\hline Unemployment & $\begin{array}{c}\text { \% unemployed } \\
\text { persons }\end{array}$ & 2832 & 0.00 & 0.21 & 0.05 & 0.03 \\
\hline Income & $\begin{array}{c}\text { \% persons with } \\
\text { weekly income> } \\
\$ 1500\end{array}$ & 2832 & 0.05 & 0.66 & 0.28 & 0.10 \\
\hline Age & $\%$ persons aged $>60$ & 2832 & 0.01 & 0.24 & 0.07 & 0.03 \\
\hline Migration ratio & \% migrants & 2832 & 0.11 & 0.70 & 0.30 & 0.11 \\
\hline Density & Persons per sq km & 2832 & 485.80 & $59,888.46$ & $5,375.10$ & $5,656.13$ \\
\hline School & $\mathrm{km}$ & 2832 & 0.00 & 3.26 & 0.90 & 0.49 \\
\hline BRT & $\mathrm{km}$ & 2832 & 0.21 & 8.86 & 2.94 & 1.75 \\
\hline CBD & $\mathrm{km}$ & 2832 & 0.41 & 10.98 & 4.53 & 2.22 \\
\hline Ferry & $\mathrm{km}$ & 2832 & 0.01 & 5.54 & 1.59 & 0.94 \\
\hline Train & $\mathrm{km}$ & 2832 & 0.02 & 4.96 & 1.48 & 0.83 \\
\hline
\end{tabular}

Note: 'Type' is a dummy variable. A value of 0 (1) for the variable 'Type' corresponds to a unit (house).

\section{$5 \quad$ Results}

\subsection{Global model}

The GWR software first determines the preferred global model from the variables in Table 1. The best model includes the variables presented in Table 1, except for the variables of distance to school and population density. A semi-log model is employed because the transformed log variable has the advantage of mitigating heteroscedasticity as a result of the reduced scale of the values (Rodriguez and Mojica 2009). Various combinations of independent variables were considered, taking account of the trade-off between increasing the number of variables and reducing the degrees of freedom.

The regression results of the preferred global model are summarized in Table 2. The adjusted Rsquare is 0.702 , suggesting that 70.2 percent of the variation in the property price can be explained by the explanatory variables. The variance inflation factor (VIF) does not suggest noticeable mutlicollinearity.

In general, most parameters present the expected signs as hypothesized. The property price is expected to be higher with more bedrooms, bathrooms, and parking spaces. Unit prices are on average lower than the house prices, as observed in most Australian capital cities. The socio-demographic variables also show expected signs, with property price being higher with a neighborhood that has a lower unemployment rate, higher income, older age, and lower migration ratio on average. 
Table 2: Global model regression results

\begin{tabular}{|l|c|c|c|c|c|}
\hline Variables & Coef. & Std. Error & t-value & Prob. & VIF \\
\hline (Constant) & 12.250 & .041 & 298.787 & 0.000 & - \\
\hline Bedrooms & .188 & .007 & 25.572 & 0.000 & 2.670 \\
\hline Baths & .136 & .009 & 15.158 & 0.000 & 1.767 \\
\hline Parking & .087 & .007 & 12.093 & 0.000 & 1.397 \\
\hline Type & -.201 & .013 & -15.639 & 0.000 & 1.737 \\
\hline Unemployment & .876 & .241 & 3.640 & 0.000 & 1.889 \\
\hline Income & .869 & .066 & 13.138 & 0.000 & 1.806 \\
\hline Age & 1.468 & .153 & 9.564 & 0.000 & 1.211 \\
\hline Migration & -.160 & .066 & -2.428 & 0.015 & 2.023 \\
\hline CBD & -.022 & .003 & -8.191 & 0.000 & 1.550 \\
\hline Ferry & -.040 & .006 & -6.573 & 0.000 & 1.381 \\
\hline Train & .041 & .007 & 6.139 & 0.000 & 1.299 \\
\hline Unemployment & .876 & .241 & 3.640 & 0.000 & 1.889 \\
\hline Observations & 2,832 & & & & \\
\hline Adj. R-squared & 0.702 & & & & \\
\hline Classic AIC & 412.06 & & & & \\
\hline AICc & 412.19 & & & & \\
\hline
\end{tabular}

In terms of accessibility variables, the negative signs of the $\mathrm{CBD}$ and Ferry variables confirm that the sold price is higher for properties located closer to the CBD and ferry terminals. Given the semi-log model form, the magnitudes of the impact on the property price can be interpreted as the influence of one unit change in the explanatory variable on the percentage change in the dependent variable. Thus, keeping everything else constant, a one kilometer decrease in the distance to the CBD is expected to increase the price by 2.2 percent on average, whereas a one kilometer decrease in the distance to the ferry terminal is expected to increase the price by 4 percent. These accessibility changes bring significant effect on property price over the study area.

The distance to train station, however, shows a positive sign, which suggests that price is generally lower for properties closer to the train stations. This appears counterintuitive since, theoretically, accessibility to train stations is expected to have a positive impact on the property value. However, in the study area-which is within 2 kilometers of the river and with the Brisbane CBD located in the center- the heavy-rail type of train service is not used as frequently as ferry or local buses by local residents. In contrast, being too close to the train stations might receive a negative impact from noise, including from coal trains, which may explain why the accessibility to train station has a negative impact on close-by property values. This effect is further explored in the GWR local model in Section 5.2.

The good fit of the global model and the significance of the explanatory variables validates the appropriateness of the model and suggests that the property prices were indeed influenced by the property attributes, socio-demographics, and the accessibility attributes in the dataset. However, the global model only shows the average relationship between the property price and the determinants for the whole study area. It is likely that there are local variations that give more informative policy implications, and this will require the use of GWR local model that is presented in Section 5.2. 


\subsection{Local model}

Using the selected explanatory variables from the preferred global model identified in Section 5.1, the GWR local model is run using GWR 4 package with adaptive kernels and a bi-square function, as expressed in Equation 4 (Fotheringham et al. 2002).

$$
W_{i j}= \begin{cases}\left(1-d_{i j}^{2} / \theta_{i(k)}\right)^{2} & d_{i j}<\theta \\ 0 & d_{i j}<\theta\end{cases}
$$

where:

$w_{i j}$ is the weight of the observation at location $j$ for estimating the coefficient at location $i$;

$d_{i j}$ is the Euclidean distance between $i$ and $j$;

$\theta_{i(k)}$ is an adaptive bandwidth size defined as the $k_{t h}$ nearest neighbor distance.

The adaptive kernels, as opposed to the fixed kernels, ensure each of the data points is estimated by the same number of neighboring data points. This approach is generally recommended for data points that are not evenly spatially distributed across a study area. This is the case here, where residential properties tend to cluster in some particular areas and other areas, such as parklands, have no property developments. The bandwidth of the kernels is determined using the "golden selection search method" embedded in GWR 4, which determines the optimal bandwidth based on small sample bias corrected AIC minimization.

In the GWR local model, each regression point is estimated by its neighboring data points within the kernel; hence, each regression point has its own parameter value. The means and the standard deviations of the local parameters for each of the variables are summarized in Table 3 together with the results of the spatial variability test.

Table 3: Local model estimation results and calibration

\begin{tabular}{|l|c|c|c|}
\hline Variable & \multicolumn{2}{|l|}{ Mean } & $\begin{array}{l}\text { Difference of } \\
\text { Criterion }\end{array}$ \\
\hline Intercept & 12.404 & 0.724 & -876.276 \\
\hline Bedrooms & 0.184 & 0.070 & -43.131 \\
\hline Baths & 0.122 & 0.072 & -17.022 \\
\hline Parking & 0.101 & 0.074 & -63.651 \\
\hline Type & -0.213 & 0.138 & -70.460 \\
\hline Unemployment & -0.520 & 2.412 & -3.037 \\
\hline Income & 0.645 & 0.890 & -257.072 \\
\hline Age & 1.084 & 1.967 & 1.669 \\
\hline Migration & -0.192 & 0.791 & -158.717 \\
\hline CBD & -0.015 & 0.183 & -644.661 \\
\hline Ferry & -0.036 & 0.200 & 17.221 \\
\hline Train & 0.064 & 0.211 & -1.300 \\
\hline Classic AIC & -396.344 & & \\
\hline AICc & -262.912 & & \\
\hline Adjusted R-square & 0.794 & & \\
\hline F-statistics & 3.53 & & \\
\hline
\end{tabular}


The local model demonstrates an improved model fit as compared with the global model, as evident by the higher adjusted R-square at 0.794 ( 0.702 in the global model) and significantly lower AIC values. The F-statistic (3.53) is used to test the model fit of the local model against the global model and is greater than the critical value of 1.76 , confirming the improvement of model fit from the global model. The differences of criterion as the indicator of spatial variability test are positive when the variables have no significant variability across the whole study area and are negative otherwise. Table 3 shows that all variables have significant spatial variability apart from Age and Ferry. It is possible to develop a mixed model from GWR 4, which treats Age and Ferry as fixed variables while other variables vary over space. While these variables do not significantly vary over the whole of the study area, this does not preclude local variability being observed; hence these variables are retained as local variables in the model. Age in particular is an important factor reflecting local travel demand patterns and socio-demographic situations (Bento et al. 2005; Coevering and Schwanen 2006; Lyons et al. 2007), and the Ferry variable is the key variable of this study's interest. The paper concentrates on accessibility effects, and we primarily present figures for the accessibility variables, including Ferry. Importantly, the interpretation of the local parameters, using maps, is against a backdrop of local significance so as not to overestimate significance.

Figure 2 shows the geographical distribution of all properties within the study area and each property is colored according to the residual values of the local model estimation. The properties appear to spread over the study area, but the distribution is generally denser in Brisbane City (also referred to as the CBD) and sparser in some areas such as the Hamilton North Shore, where some industrial uses remain and where redevelopment has only recently commenced. This identification implies that the adaptive bandwidth as opposed to the fixed bandwidth adopted in this study is appropriate. The residual plot does not demonstrate any noticeable patterns, which again confirms the good model fit of the local model.

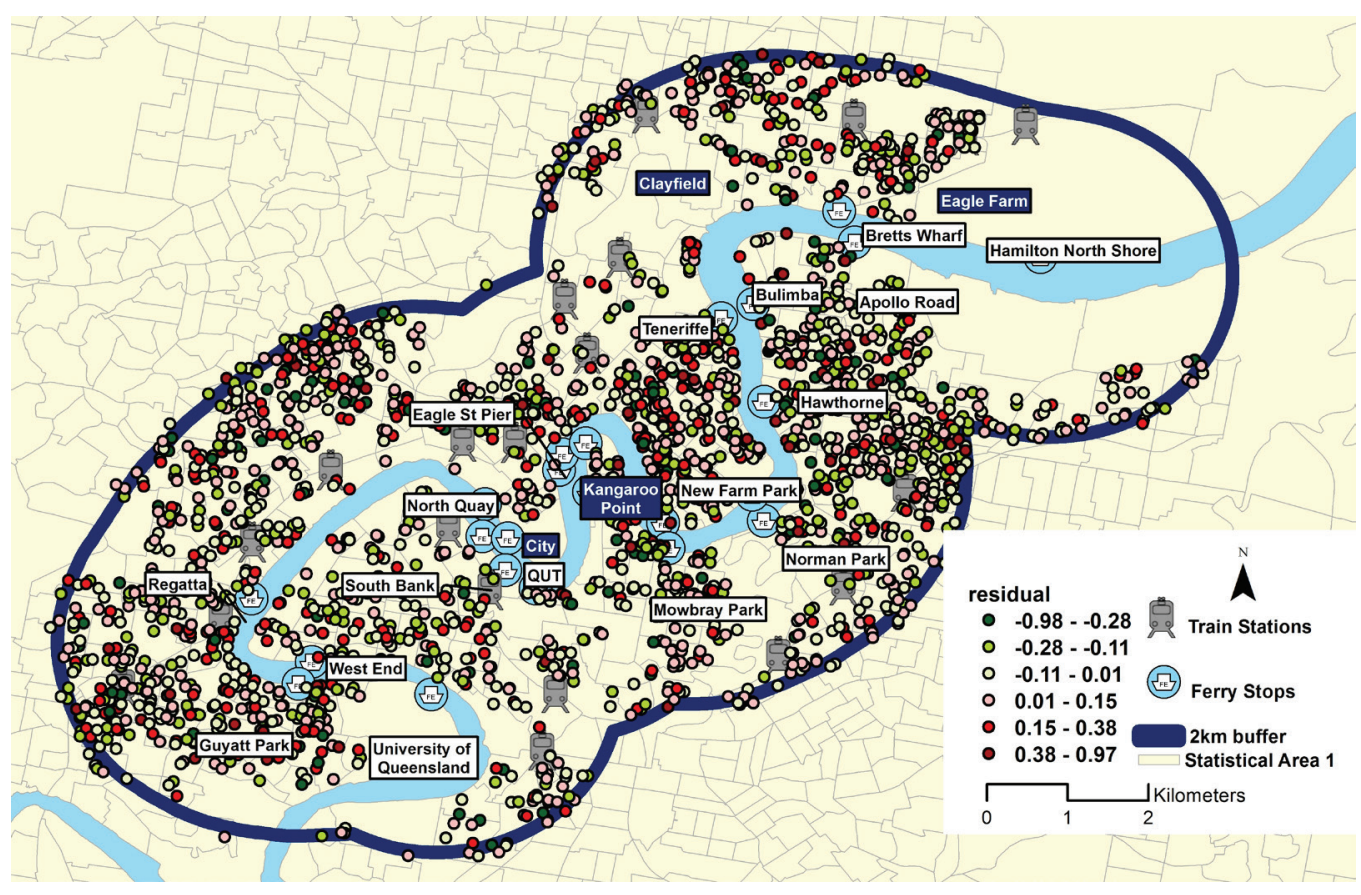

Figure 2: Residuals of the GWR local model estimation 
The local parameter value of each data point can be plotted on GIS layers for clearer visualization of the spatial variation. Figure 3 displays the local parameter estimates of the ferry variable, where properties with insignificant parameter values are excluded from the map. The properties colored in green receive a negative impact from the increasing distance to ferry terminals; that is, properties closer to the ferry stops have higher values as expected. In contrast, the properties colored in red show the reverse impact from the distance to the ferry terminals, and this is further discussed below.

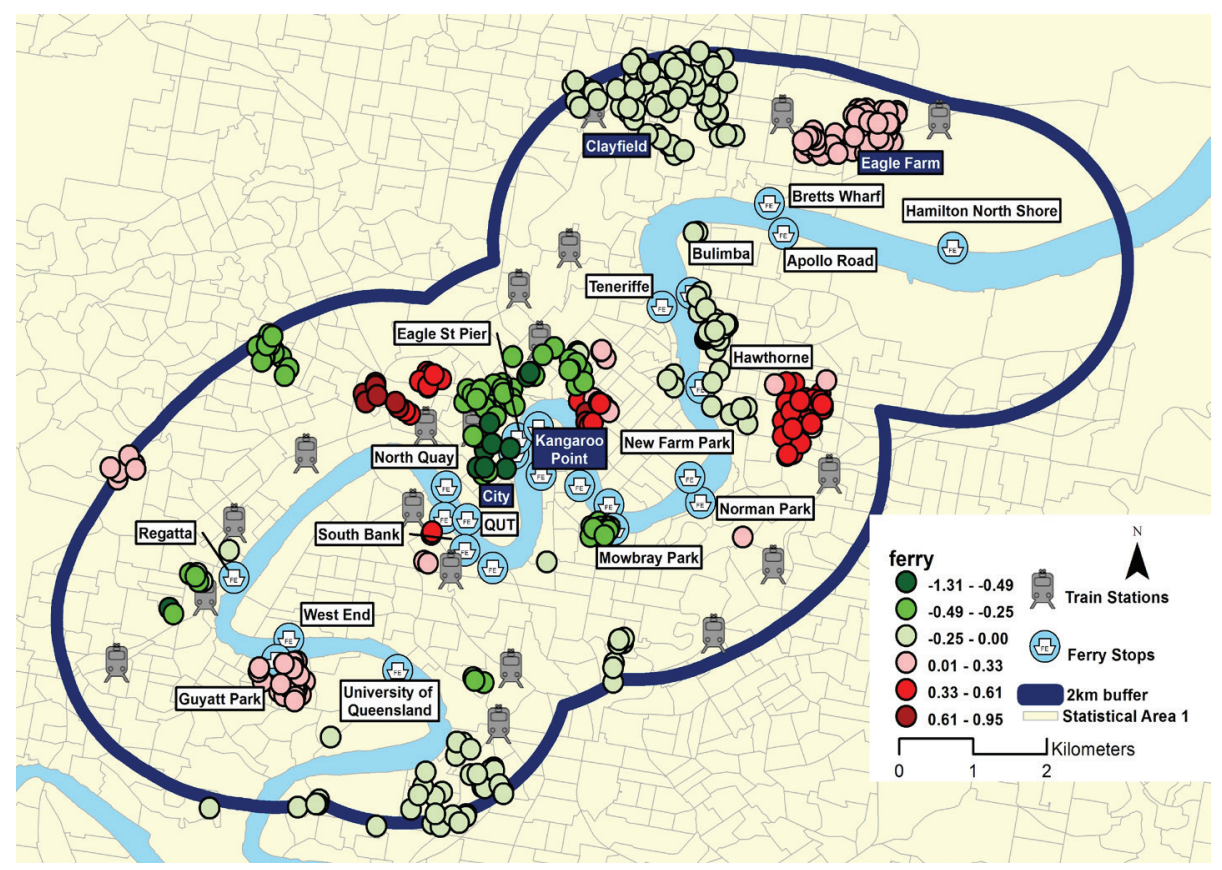

Figure 3: The spatial variation of the distance to ferry variable

The negative signs (which refer to positive effects) for the Regatta, Bulimba, and Hawthorne terminals, and to a lesser extent at Mowbray Park, are all as hypothesized. This suggests the combination of suburbs with mature terminals and a decade of ferry-oriented development has produced positive results. No such effects were observed at Tenerife or Hamilton North Shore, where development is still immature. And the effects are more muted at locations such as West End, where redevelopment opportunities have been scarce, partly due to planning controls, and at the QUT Gardens Point and University of Queensland terminals, which are dominated by higher education land uses.

There are three major ferry services in our case study, including CityCat, CityHopper, and CityFerry services. Both CityCat and CityHopper provide linear river services, and the Mowbray Park terminal is serviced by both services. However, the nearby Norman Park terminal is only serviced by CityFerry, which provides more limited, lower-frequency cross-river services only. As expected, there are positive effects on property values surrounding the Mowbray Park terminal but negligible effects around the nearby Norman Park terminal.

The ferries appear to have little influence on property values at the three key Kangaroo Point terminals (Dockside, Thornton St, and Holman St), contrary to expectations. Of the other unexpected results, the ferries appear to have had significant effects on property values on the Brisbane reach of the river, particularly on the cluster of high-rise residential apartment buildings that have emerged adjacent to or north of the Eagle Street and Riverside terminals in recent decades. But the ferries have had negligible effect on property values on the western side of the CBD at North Quay and at South Bank, 
where residential properties are much fewer in number and where commercial, government, parkland, and cultural land-uses predominate. Similarly, there is little effect at Apollo Road, where industrial land uses are foremost. This maybe as a result of the non-residential uses internalizing the land value increases prior to residential development.

The unexpected positive sign (negative influence) on property values observed around the Guyatt Park terminal may be explained by the immediate presence of the large University of Queensland St Lucia campus, which was not included in the model as a separate variable and may be significantly affecting the results since properties around this site are more dedicated to student use. The positive signs identified to the east of the Hawthorne terminal may be a result of their relatively long distance to the terminal. Residents in this area may prefer using train or other means of travel that are more accessible than the ferry terminal.

The results surrounding the Bretts Wharf terminal are intriguing. To the northwest of the terminal lies the suburb of Clayfield, a hilltop enclave of large mansions that is one of the city's most prestigious suburbs. This area seems to benefit significantly from accessibility to the ferry terminal. Yet the (relatively) lower-income area to the northeast in Hamilton and Eagle Farm appears to be negatively affected. This discrepancy is likely due to factors not included in the model, such as the presence of large racecourse precincts and some remaining industrial uses around Eagle Farm.

The properties that benefit most from the accessibility to ferry appear to be those high-rise apartments in the Brisbane City area shown by the darkest green color. The parameter values here range between -0.49 and -1.31 , suggesting that, everything else being equal, a 100-meter decrease in the distance to the ferry stop would increase property values by between 4.9 and 13.1 percent. This is considerably stronger response than is revealed by the global model, which identifies a 4 percent increase on average. This strong relationship is likely to be partly due to the better accessibility to the ferry and partly as a result of good water views, which adds value to high-rise apartments in the city center.

The distance to train stations, as the other measure of the accessibility to public transport, is displayed in Figure 4. As discussed in the global model in Section 5.1, train stations appear to have a negative impact on the property price, given the positive sign of the distance to train parameter. This finding is affirmed by Figure 4, which shows that only in the Brisbane CBD are any positive accessibility effects (negative parameter signs) identified. This is possibly because people living in the Brisbane CBD value trains more than residents elsewhere since here the major advantage of the train service is to access outer suburbs rather than the inner city of this study area. In contrast, people living in this study area tend to use buses to access the Brisbane $\mathrm{CBD}$, which provide a more frequent service with less travel time. The train stations are also on corridors for rail freight, especially large numbers of coal train movements, which provide air and noise pollution concerns for adjacent properties. 


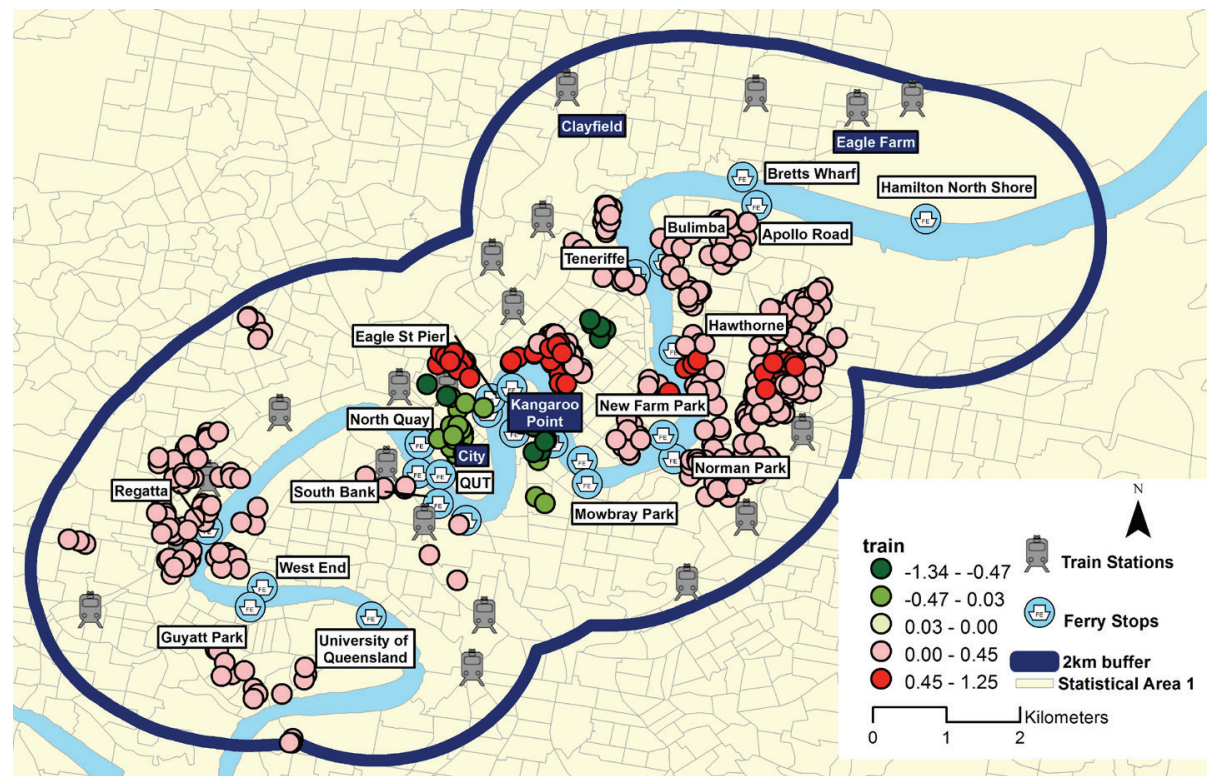

Figure 4: The spatial variation of the distance to train variable

Brisbane, as with other Australian capital cities, has developed so that accessibility to the CBD is highly valued as the business and activity center of Southeast Queensland. The positive impact of accessibility to the CBD on property values appears to be particularly evident north of the North Quay terminal and in the northeast portion of the CBD, where the darkest green color is present. The magnitude of this impact can be as great as a 9.4 percent increase in house price for a property 100 meters closer to the $\mathrm{CBD}$. However, reverse signs are identified to the north of the Eagle Street terminal and to the southwest of the Teneriffe terminal, as well as the Norman Park terminal. It should be remembered that this variable is highly correlated with access to buses and therefore, the interpretation of accessibility to CBD includes bus accessibility.

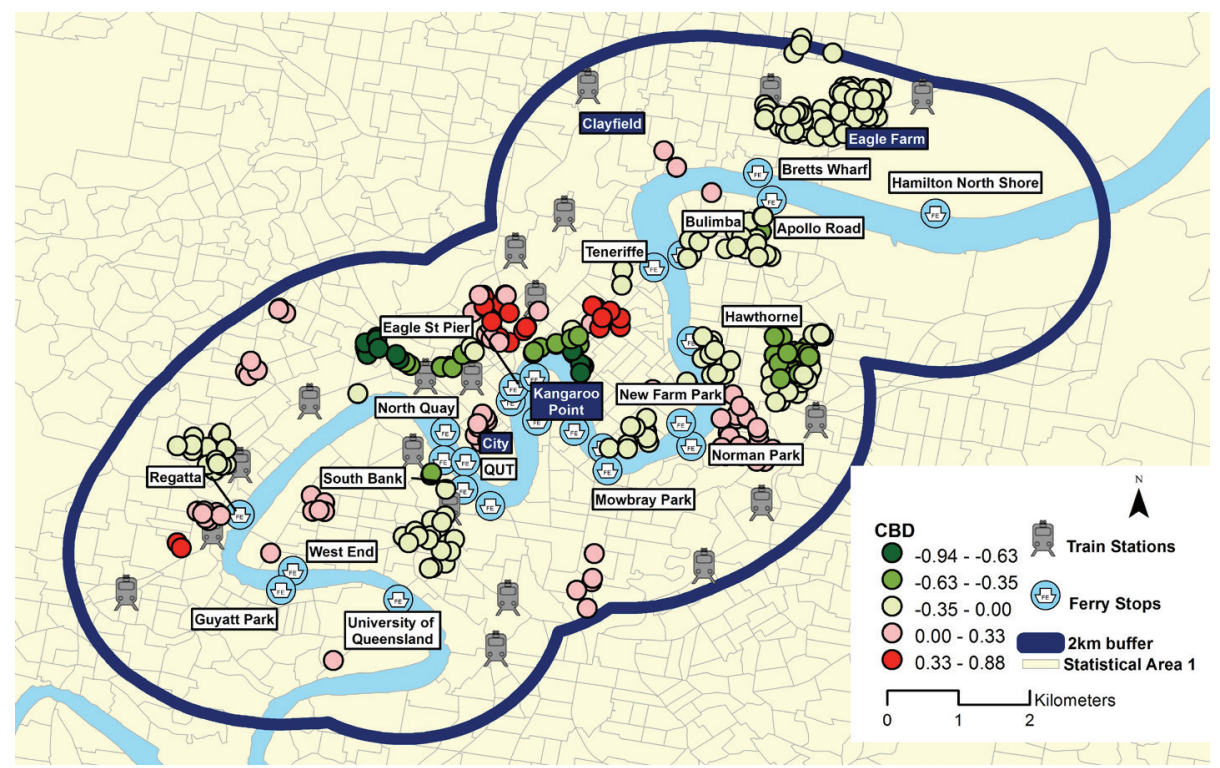

Figure 5: The spatial variation of the distance to $\mathrm{CBD}$ variable 


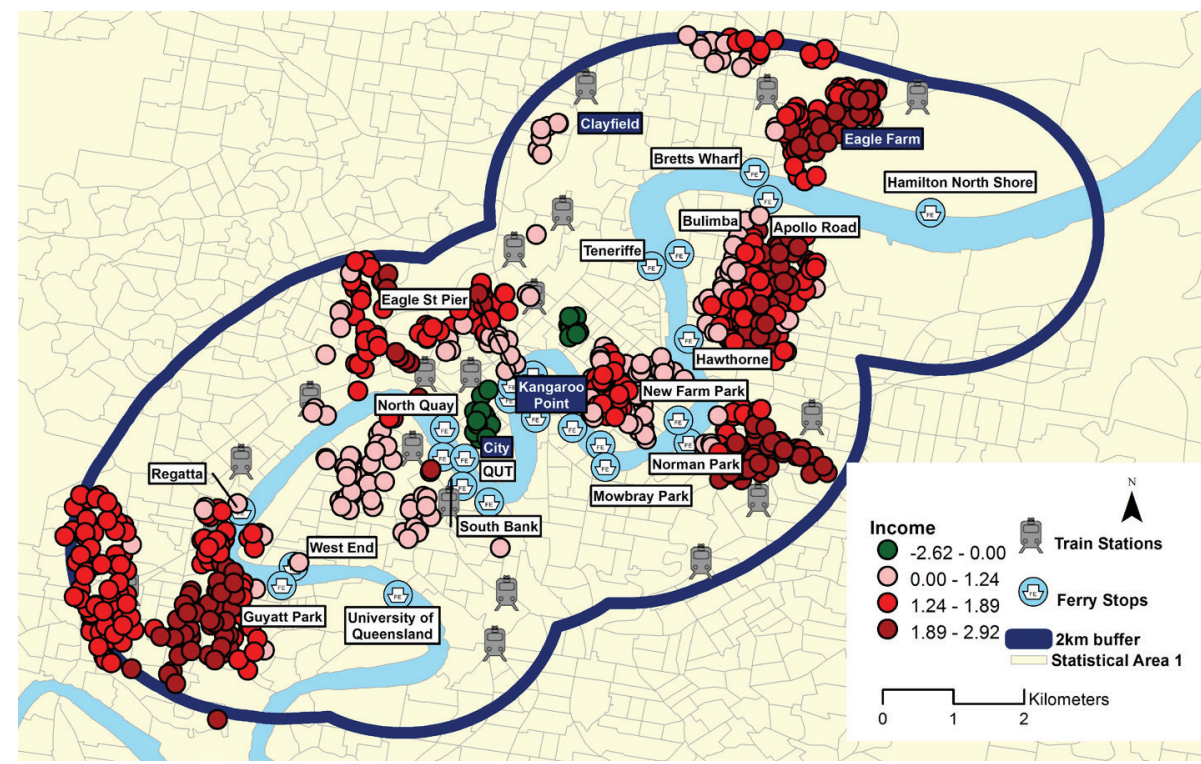

Figure 6: The spatial variation of the income variable

The income variable is more consistent across the study area, with the same positive sign as in the global model. However, it is interesting to note that income is identified as having a negative impact in the Brisbane CBD. This is not surprising given that there tends to be more rental tenants living in the $\mathrm{CBD}$. This group of residents is usually younger with relatively lower incomes, but the property price is higher. In turn, this results in the negative relationship between the residents' income and the property price in the city.

The property attributes, including bedrooms, bathrooms, parking, and type, have consistent signs over the study area. For example, the positive impact of bedrooms on property prices is identified in Figure 7, with many more data points being significant and no unanticipated signed parameter estimates as seen previously in the maps for the accessibility and socio-demographic variables. The maps for bathrooms, parking, and type are similarly consistent and are not shown here. This implies that the importance of property attributes on property value is similar across the study area, unlike other variables that show reversed signs in some areas. 


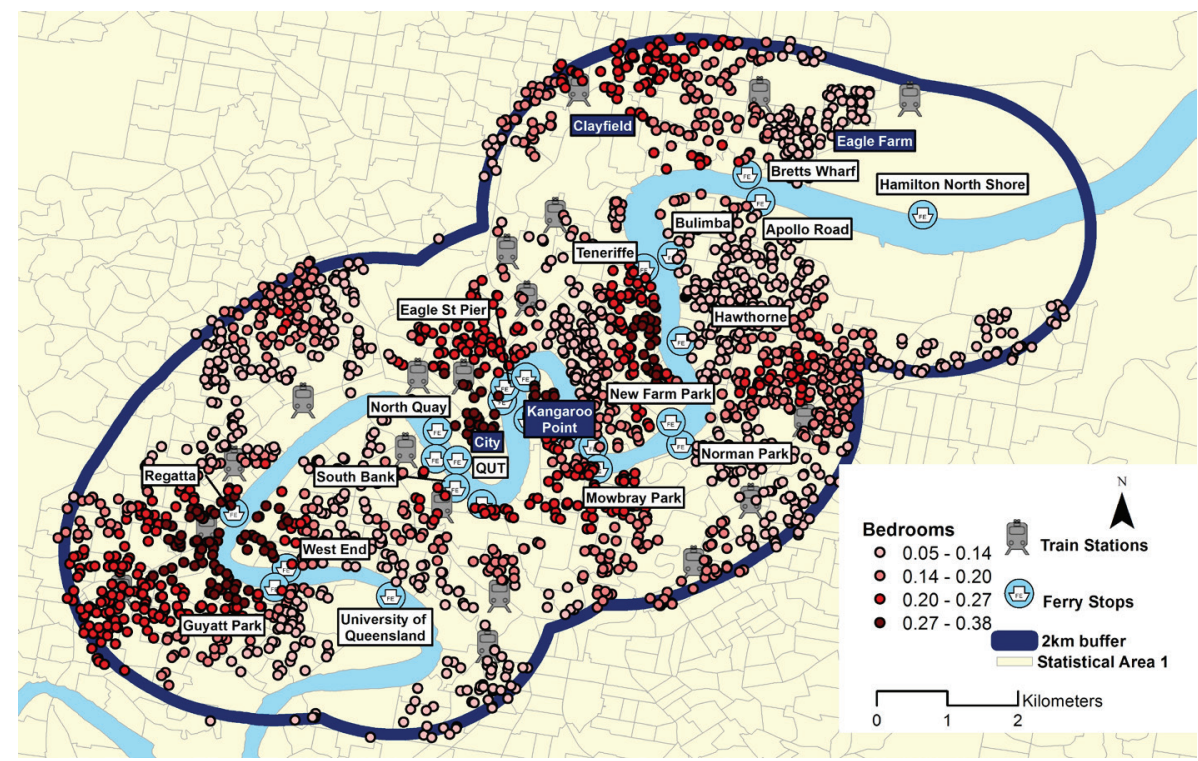

Figure 7: The spatial variation of the bedroom variable

\section{Discussion}

This paper uses a GWR approach to identify the impact of the accessibility to ferry services on residential property prices in the central area of Brisbane. A global model and a local model are employed by controlling the property characteristics and neighborhood features so that values of accessibility to different public transport and other locations can be observed. The price models demonstrate good model fits in both global and local models.

Focusing on the benefit of the ferry services, the land value gains are identified as higher around the Bulimba, Hawthorne, and Regatta terminals as a result of the greater redevelopment potential and the maturity of new development surrounding the ferry terminals. More positive effects are identified at the Mowbray Park terminal, which is on the CityCat route, as compared to the Norman Park terminal, which has low-frequency CityFerry services. By contrast, very little land value uplift is identified around the Tenerife and North Shore Hamilton terminals as these have only entered service in the last two years and redevelopment remains limited at these locations. Very little effect is observed around the University of Queensland and QUT Gardens Point terminals (the latter servicing the large Queensland University of Technology campus adjacent to the Brisbane CBD), where few private properties are within close proximity and education land uses dominate. Positive effects were expected at the Kangaroo Point terminals of Dockside, Holman Street, and Thornton Street, all of which are serviced by the CityHopper route. This is, however, not evident from the local model estimation results, possibly because people living in this area tend to use buses that provide a more frequent service and shorter travel time than ferries. This is somewhat confirmed by the increase in home price as a result of proximity to the CBD (which is highly correlated with accessibility to bus).

The research findings in general confirm that property values in the study area do benefit from accessibility to ferries, especially in areas where residential redevelopment has taken place around the ferry terminals. Being close to a ferry terminal in the inner Brisbane CBD adds to property values, in contrast to being close to trains, which is designed more to serve outer suburbs. This suggests that, like other rapid transit services, ferries can potentially generate substantial economic benefits as long as they 
are designed as a frequent and rapid service with a sufficiently wide geographical coverage, connecting major business centers and attractions.

The implications are that property developers are justified in seeking to secure ferry terminals to service their developments. Governments may also be justified in bringing in land value capture mechanisms to help pay for terminals, vessels, or operating costs in appropriate locations.

Future research will focus on the investigation of other potential price determinants that may influence some particular areas as discussed in Section 5.2, including the role of large university campuses, as well as employing the mixed GWR model instead of the local model used in this study. A further segmentation of the study area by the creation of different catchment buffers around ferry terminals will also be considered as ways of further improving model fit and interpretation. Furthermore, the current study uses distance to evaluate the accessibility of ferry systems. The distance to the nearest ferry might be highly correlated with water views that may be viewed as an amenity for landholders. The separation of ferry effects and water view effects is worthy of exploration, though methodologically difficult since they are likely to be highly correlated. Other relevant variables, such as public transport frequencies, service coverage, connections, price of public transport, land-use types, and built environment attributes, are potentially of interest in explaining and controlling for the impact of ferry accessibility on value uplift and are part of future research.

\section{$7 \quad$ Acknowledgments}

The acquisition of data has been supported by a University of Sydney Business School grant. Transport research at Griffith University's Urban Research Program is supported by the Academic Strategic Transport Research Alliance, involving the Queensland Government Department of Transport and Main Roads, the Motor Accident and Insurance Commission, and Queensland Motorways Limited. The authors are grateful for the assistance of Dr Liang Ma in the production of the maps. The views expressed are solely those of the authors, who are responsible for all errors and omissions. 


\section{References}

Alonso, W. 1964. Location and Land Use. Cambridge: Harvard University Press.

Bento, A. M., M. L. Cropper, A. M. Mobarak, and K. Vinha. 2005. The effects of urban spatial structure on travel demand in the United States. The Review of Economics and Statistics 87(3): 466-478.

Blainey, S. P. 2010. Trip end models of local rail demand in England and Wales. Journal of Transport Geography 18(1): 153-165.

Burke, M. and A.L. Brown. 2007. Distances people walk for transport. Road \& Transport Research 16(3): 16-29.

Burke, M. and N. Sipe. Ferries and catastrophic floods: experiences and learnings in Brisbane and New York. Accepted for presentation at the 2014 Annual Conference of the Transportation Research Board. Washington, D.C. Washington, D.C. Available at onlinepubs.trb.org/onlinepubs/tcrp/tcrp_ rpt_102.pdf. Downloaded November 25, 2013.

Cervero, R. and C. D. Kang. 2011. Bus rapid transit impacts on land uses and land values in Seoul, Korea. Transport Policy 18: 102-116.

Cervero, R., S. Murphy, C. Ferrell, N. Goguts, and Y. H. Tsai. 2004. Transit-oriented development in the United States: experiences, challenges, and prospects. Washington, DC: Transportation Research Board.

Coevering, P. V. D. and T. Schwanen. 2006. Re-evaluating the impact of urban form on travel patterns in Europe and North America. Transport Policy 13: 229-239.

Debrezion, G., E. Pels, and P. Rietveld. 2007. The impact of railway stations on residential and commercial property value: A meta-analysis. The Journal of Real Estate Finance and Economics 35(2): 161-180.

Du, H. and C. Mulley. 2006. Relationship between transport accessibility and land value: a local model approach with geographically weighted regression, Transportation Research Record: Journal of the Transportation Research Board 301.

— 2007. Transport Accessibility and Land Value: A Case Study of Tyne and Wear. RICS Research Paper Series 7(3). www.rics.org.

Fotheringham, A. S., C. Brunsdon, and M.E. Charlton. 2002. Geographically Weighted Regression: The Analysis of Spatially Varying Relationships. Chichester, UK: Wiley.

Hoffman, A. 2008. Advanced Network Planning for Bus Rapid Transit: The Quickway Model as a Modal Alternative to Light Rail Lite. Washington, DC: Federal Transit Administration, USDOT.

Lochl, M. and K. M. Axhausen. 2010. Modeling hedonic residential rents for land use and transport simulation while considering spatial effects. The Journal of Transport and Land Use 3(2): 39-63.

Lyons, G., J. Jain, and D. Holley. 2007. The use of travel time by rail passengers in Great Britain. Transportation Research Part A 41: 107-120.

Muth, R. F. 1969. Cities and Housing. Chicago: University of Chicago Press.

Nelson, A. C. 1992. Effects of elevated heavy-rail transit stations on house prices with respect to neighborhood income. Transportation Research Record 1359: 127-132.

Perk, V. and M. Catala. 2009. Land Use Impacts of Bus Rapid Transit: Effects of BRT Station Proximity on Property Values Along the Pittsburgh Martin Luther King, Jr. East Busway. FTA-FL report 267109.2009.6. www.nbrti.org.

Rodriguez, D. A. and C. H. Mojica. 2009. Capitalization of BRT network expansions effects into prices of non-expansion areas. Transportation Research Part A 43: 560-571.

Sipe, N. and M. Burke. 2011. Can river ferries deliver smart growth? Transportation Research Record: Journal of the Transportation Research Board 2217: 79-86. 
State of Queensland (Transport of Main Roads). 2012. Travel in south-east Queensland. An analysis of travel data from 1992 to 2009.

Thompson, R., R. Burroughs, and T. Smythe. 2006. Exploring the connections between ferries and urban form: some considerations before jumping on board. Journal of Urban Technology 13(2): 25-52.

Von Thunen, J. H. 1826, Der isolierte Staat, translated to English by Wartenberg, C. 1966. Von Thunen's Isolated State: An English Edition of Der Isolierte Staat. Pergamon Press.

Weisbrod, R. E. and C. T. Lawson. 2003. Ferry systems: Planning for the revitalization of US cities. Journal of Urban Technology 10(2): 47-68. 